\title{
Modeling of inherent anisotropic behavior of partially saturated clayey rocks
}

\author{
Dawei $\mathrm{Hu}^{\mathrm{a}, \mathrm{b}}$, Hui Zhou ${ }^{\mathrm{a}, *}$, Fan Zhang ${ }^{\mathrm{c}}$, Jianfu Shao ${ }^{\mathrm{b}}$, Junfeng Zhang ${ }^{\mathrm{d}}$ \\ a State Key Laboratory of Geomechanics and Geotechnical Engineering, Institute of Rock and Soil Mechanics, Chinese Academy of Sciences, Wuhan 430071, China \\ ${ }^{\mathrm{b}}$ LML, UMR8107, CNRS, University of Lille I, Villeneuve d'Ascq, France \\ ${ }^{\mathrm{c}}$ Hubei University of Technology, Wuhan 430068, China \\ ${ }^{\mathrm{d}}$ Key Laboratory for Hydrodynamics and Ocean Engineering, Institute of Mechanics, Chinese Academy of Sciences, Beijing 100190, China
}

\section{A R T I C L E I N F O}

\section{Article history:}

Received 18 May 2012

Received in revised form 6 September 2012

Accepted 7 September 2012

Available online 30 October 2012

\section{Keywords:}

Inherent anisotropy

Unsaturated

Discrete approach

Clayey rocks

\begin{abstract}
A B S T R A C T
Clayey rocks are frequently chosen as a geological barrier material for underground repositories. The inherent anisotropic mechanical behavior and the evolution of mechanical behavior with water content are two crucial material properties for the safety analysis of these structures. The present paper focuses on numerical modeling of the inherent anisotropy and the effect of water content, as well as the interactions of these properties in partially saturated clayey rocks with preferably oriented bedding planes. A discrete thermodynamic approach is adopted for describing the inherent anisotropic mechanical behavior, and the anisotropy of the elastic parameters, plastic evolution and damage evolution are considered. Capillary pressure is introduced to describe the effect of the water content with the help of the effective stress concept, and a procedure for the identification of the model parameters is presented. Finally, the proposed model is applied to a study of triaxial compression tests of argillite with different orientations of the bedding planes and variable water content. In summary, the main features of the studied material are well reproduced by the model.
\end{abstract}

(c) 2012 Elsevier Ltd. All rights reserved.

\section{Introduction}

Due to favorable geological properties characterized by the absence of major fractures, very low permeability and high mechanical strength, clayey rock is frequently chosen as a possible geological barrier material, such as that used for the capping rock in deep geological storage of $\mathrm{CO}_{2}$ and underground repositories for nuclear waste. In the context of underground storage of nuclear waste, the initially saturated argillites will be submitted to various coupled perturbations, such as mechanical loading due to excavation, water and gas flow, de-saturation and re-saturation. Due to the presence of clay elements such as smectite, the mechanical behavior of argillites is very sensitive to the saturation degree. A number of experimental investigations [1-10] have been performed on various clayey rocks in partially saturated conditions. Certain constitutive models have been proposed using the concept of effective stresses on the partially saturated field. Recently, certain alternative approaches [11-16] have been presented for the modeling of partially saturated geomaterials.

Inherent anisotropy is another important property of clayey rocks. This class of rocks usually exhibits a selected preferable orientation of distinct bedding planes, which result in inherent anisotropic behavior on the macro-scale. A large body of research $[10,17-27]$ has been conducted on inherently anisotropic rocks,

\footnotetext{
* Corresponding author.

E-mail address: hzhou@whrsm.ac.cn (H. Zhou).
}

including experimental characterization, theoretical studies and numerical modeling. Various topics have been covered, including micro- and macro-structural factors in anisotropy and the interactions between inherent and induced anisotropies. According to experimental investigations [10], this anisotropic behavior becomes less and less pronounced as the water content degree increases.

However, to our knowledge, there is still no published constitutive model that can describe the two effects of capillary pressure and inherent anisotropy as well as their interaction in clayey rocks. The present work aims to model the behavior of inherently anisotropic clayey rocks under the effect of variable water content degree. The presented model applies the effective stress concept within the existing discrete approach. Section 2 summaries the previous experimental results on mechanical behavior of clayey rocks, including the saturation degree and the inherent anisotropy. Based on these experimental results, Section 3 proposes a discrete damage-plasticity model for inherently anisotropic clayey rocks with consideration of the effect of capillary pressure. Finally, the numerical algorithm, identification of model parameters and the numerical results are given in the last section.

\section{Summary of experimental investigations}

A comprehensive experimental program has been carried out on argillite (including Tournemire argillite and Meuse/HauteMarne argillite) at the Lille Laboratory of Mechanics, and the 
results have been reported by Niandou et al. [23], Chiarelli et al. [4] and Zhang et al. [10]. A short summary of test data on argillite is given in this section, and these data will be used in Section 4 to validate the numerical predictions. The average volumetric fractions of various mineral phases of Tournemire argillite and Meuse/ Haute-Marne argillite are $15 \%$ and $27 \%$ for calcite, $19 \%$ and $23 \%$ for quartz, $44 \%$ and $45 \%$ for clay matrix, respectively. The representative porosity of Tournemire argillite and Meuse/Haute-Marne argillite are in the range of $8 \%$ and $11.8 \%$, respectively.

\subsection{Mechanical behavior of Tournemire argillite with natural water content}

According to porosity and natural water content tests, the natural water content of Tournemire argillite is approximately $8 \%$, and the initial saturation degree is nearly $95 \%$. Hydrostatic compression tests have shown that there is a difference in strain between the parallel and perpendicular directions relative to the natural bedding plane; this difference indicates an initial anisotropy in the argillite. The effects of inherent anisotropy on elastic behavior and strength properties were analyzed based on a series of triaxial compression tests performed on samples with different orientations of the bedding planes. Fig. 1 presents the evolution of the axial Young's moduli and strength with respect to the orientation of the bedding planes. The axial Young's modulus is the lowest at $\theta=0^{\circ}$ (i.e., when the bedding planes are normal to the loading direction, this value continuously increases with the orientation of the bedding planes). Fig. 1 shows that that the failure stress of the argillite depends on the orientation of the bedding planes, and there are two maximum values that occur at $\theta=0^{\circ}$ and $\theta=90^{\circ}$. The minimum strength is found between $\theta=30^{\circ}$ and

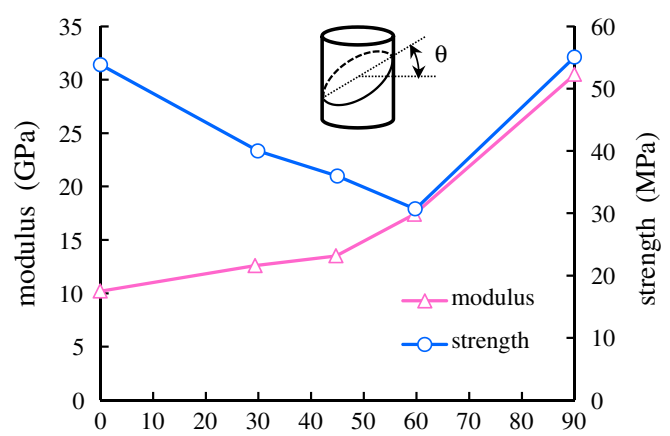

Fig. 1. Variation of axial Young's modulus and strength vs. orientation of bedding planes with a confining pressure of $5 \mathrm{MPa}$ (after [23]).

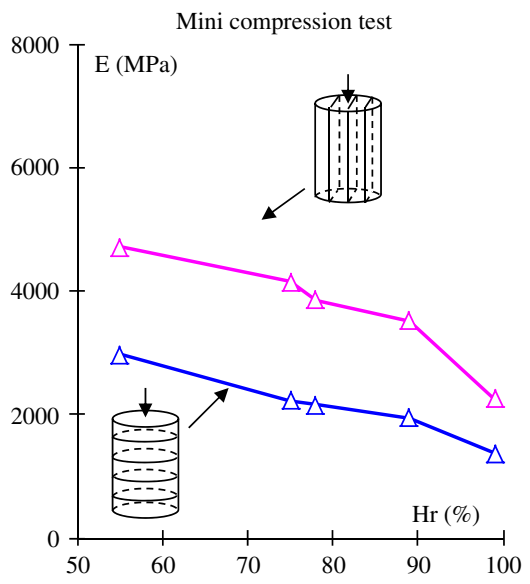

$\theta=60^{\circ}$. This anisotropy of the strength is related to the failure mechanism. In general, the fracture angle strongly depends on the bedding plane orientation, and the failure occurs in two principal modes, extension and shearing. However, fractures can develop both in the argillite matrix and in the bedding planes.

\subsection{Effect of water content on mechanical behavior of Meuse/Haute- Marne argillite}

To study the influence of water content on the mechanical behavior of Meuse/Haute-Marne argillite, micro-indentation and mini-compression tests were performed in the parallel and perpendicular directions on samples with respect to the bedding planes and under different levels of relative humidity. As the relative humidity decreases, both the elastic modulus and failure strength increased in both the parallel and perpendicular directions, and the plastic deformation became less and less pronounced (see Fig. 2). The capillary pressure due to de-saturation, which plays a role similar to the confining stress and therefore affects the mechanical behavior, can explain this observation. When comparing the mechanical behavior of argillite in the parallel and perpendicular directions, anisotropic behavior is observed in the elastic modulus and mechanical strength. This anisotropic behavior becomes less and less pronounced as the relative humidity increases, which means that the elastic modulus and mechanical strength of a sample with perpendicular bedding planes $\left(\theta=0^{\circ}\right)$ is more sensitive to the saturation degree than that with parallel bedding planes $\left(\theta=90^{\circ}\right)$.

\section{Formulation of discrete plastic damage model for partially saturated material}

Following the above experimental investigations, a general framework is set up for the modeling of plastic damage in partially saturated material. The discrete thermodynamic approach is adopted to describe the inherent anisotropy and induced anisotropic mechanical behavior. Capillary pressure is introduced to describe the influence of water content on the mechanical behavior, and hydric responses (variations of fluid pressures with mass change and skeleton deformation) are not considered in this work (see [28]).

\subsection{General framework}

The general framework of the coupled plastic damage model in partially unsaturated conditions is first presented under the

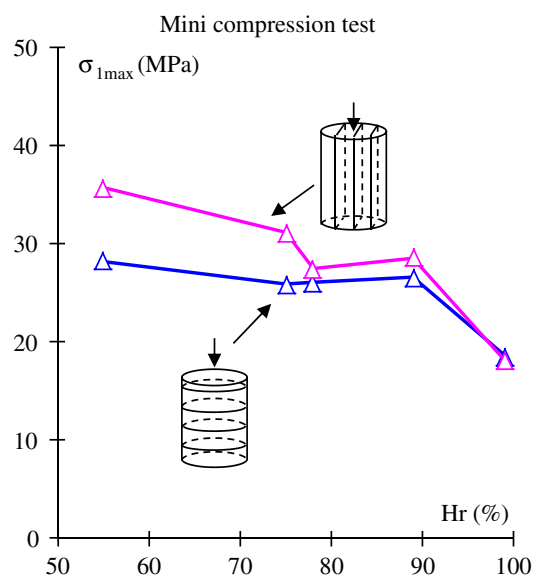

Fig. 2. Evolution of elastic modulus and peak stress as functions of relative humidity; comparisons between two bedding plane orientations (after [10]). 
assumption of small evolutions and isothermal conditions. We consider a representative volume element (RVE) of a porous medium subjected to macroscopic stresses $\boldsymbol{\Sigma}$ and partially saturated by a liquid phase $(l q)$ and a gas mixture $(\mathrm{gm})$. The gas mixture is a perfect mixture of dry air $(d a)$ and vapor $(v p)$. Let $d \mathbf{\Sigma}, \mathrm{d} p_{l q}$ and $\mathrm{d} p_{g m}$ denote incremental variations of the stress, pressure of the liquid phase and pressure of the gas mixture, respectively, and $\mathrm{d} \bar{\varepsilon}$ denote incremental variations of the macroscopic strain. The incremental variations of strain can be decomposed into elastic parts $\mathrm{d} \bar{\varepsilon}^{e}$ and plastic parts $\mathrm{d} \bar{\varepsilon}^{p}$ :

$\mathrm{d} \overline{\boldsymbol{\varepsilon}}=\mathrm{d} \overline{\boldsymbol{\varepsilon}}^{e}+\mathrm{d} \overline{\boldsymbol{\varepsilon}}^{p}$

The nonlinear poroelastic behavior is described using the model proposed by Coussy et al. [28]. This model is based on the thermodynamics of partially saturated porous media. Because only the isotherm condition is considered here, the constitutive equation is expressed as follows:

$\boldsymbol{\Sigma}=\mathbb{C}\left(p_{c p}, \boldsymbol{\omega}\right):\left(\overline{\boldsymbol{\varepsilon}}-\overline{\boldsymbol{\varepsilon}}^{p}\right)-\boldsymbol{\alpha}\left(p_{c p}\right)\left(p_{g m}-S_{l q} p_{c p}\right)$

where the fourth-rank tensor $\mathbb{C}\left(p_{c p}, \boldsymbol{\omega}\right)$ represents the elastic stiffness of the damaged porous material under partially saturated conditions, it is thus a function of the damage variable $\boldsymbol{\omega}$ and capillary pressure $p_{c p}$. The symmetric second-rank tensor $\boldsymbol{\alpha}\left(p_{c p}\right)$ defines the anisotropic Biot coefficients of the partially saturated material, which are dependent on capillary pressure $p_{c p}$. It is noted that the skeleton deformation has a strong effect on hydraulic behavior according to previous investigations [29-31]. However, for simplicity, we only consider influence of capillary pressure on mechanical behavior of partially saturated material in this paper. Hydric responses (variations of fluid pressures with mass change and skeleton deformation) are not detailed here (see [29-31]).

Denoting $p_{x}$ as the pressure of phase $x(x=l q, v p, d a)$, the gas mixture pressure rate $\dot{p}_{g m}$ and the capillary pressure rate $\dot{p}_{c p}$ are, respectively, defined as follows:

$\dot{p}_{g m}=\dot{p}_{v p}+\dot{p}_{d a}, \quad \dot{p}_{c p}=\dot{p}_{g m}-\dot{p}_{l q}$

Previous investigations $[29,30,32,33]$ show than the relationship between capillary pressure and saturation degree in most porous media is hysteretic. However, for simplicity, this hysteretic relationship is not considered and the Kelvin's law is adopted in the present work:

$\ln \left(H_{r}\right)=-\frac{M_{v p}^{o l}}{R T \rho_{l q}} p_{c p}$

where $H_{r}$ is the relative humidity and $\rho_{l q}$ the volume mass of liquid. $M_{v p}^{o l}, R$ and $T$ are the molar mass of vapor, the universal gas constant and the absolute temperature, respectively.

\subsection{Discrete formulation for plastic damage modeling}

As shown above, the plastic damage model of partially saturated materials should be based on a proper description of the dry materials. The material damage generates an induced anisotropy due to preferential orientation of microcracks. In the present work, we adopt the discrete thermodynamic approach proposed by Zhu et al. [34]. The advantage of this approach lies in the combination of micromechanical considerations for the description of physical mechanisms at the mesoscale and the phenomenological formulations used to keep the mathematical formulation as simple as possible. It is assumed that the porous material is weakened by a distribution of microcracks, defeats and weakness planes (for convenience, the term 'microcrack' will be used herein to designate all types of defeats). In terms of the consequences of microcracks on macroscopic behaviors, the random microcracks can be equivalently represented by $m$ families of parallel penny-shaped microcracks. Each family is characterized by its normal unit vector, n. The presence of microcracks induces local displacement discontinuities and additional macroscopic strains. Thus, the macroscopic strains are inherently related to local frictional sliding along the microcracks. This frictional sliding generates not only shear strain, represented by the vector $\gamma$, but also normal strain identified by the scalar variable $\beta$. Therefore, the overall plastic strain $\bar{\varepsilon}^{p}$ can be defined as the weighted sum of the local plastic strains related to all families of microcracks:

$$
\begin{aligned}
\overline{\boldsymbol{\varepsilon}}^{p} & =\sum_{r=1}^{m} \boldsymbol{\rho}^{r} \overline{\boldsymbol{\varepsilon}}^{p, r}, \overline{\boldsymbol{\varepsilon}}^{p, r}=\beta^{r} \mathbf{n}^{r} \otimes \mathbf{n}^{r}+\frac{1}{2}\left(\boldsymbol{\gamma}^{r} \otimes \mathbf{n}^{r}+\mathbf{n}^{r} \otimes \boldsymbol{\gamma}^{r}\right), \quad r \\
& =1 \ldots, m
\end{aligned}
$$

The local plastic strain of the $r$ th family is denoted by $\overline{\boldsymbol{\varepsilon}}^{p, r}$, and $\rho^{r}$ is the weighting coefficient. In the following, for the sake of simplicity, the statement $r=1 \ldots, m$ will be omitted unless specifically mentioned; thus, the variable $r$ will implicitly refer to the crack families ranging from 1 to $m$. The scalar-valued function $\omega(\mathbf{n})$ is introduced to represent the spatial distribution of the damage state related to all families of microcracks. Thus, according to Eq. (2), the constitutive relations of partially saturated materials can be written as follows:

$\boldsymbol{\Sigma}=\mathbb{C}\left(p_{c p}, \omega(\mathbf{n})\right):\left(\overline{\boldsymbol{\varepsilon}}-\overline{\boldsymbol{\varepsilon}}^{p}\right)-\boldsymbol{\alpha}\left(p_{c p}\right)\left(p_{g m}-S_{l q} p_{c p}\right)$

The objective here is to determine the plastic strains and damage state for each family of microcracks. It is assumed that the local evolution of plastic strain and damage is controlled by local stresses, which are different among the families of microcracks. Therefore, even if the damage state of each family is represented by a scalar variable, the overall damage evolution is clearly anisotropic due to the non-uniform distribution of microcrack density in each family. The local stresses applied to each family of microcracks can be obtained by a general projection technique. More specifically, for the $r$ th family of microcracks, the local stress state is characterized by the normal stress $\sigma_{n}^{r}$ and shear stress $\sigma_{t}^{r}$, which are defined by the following:

$\sigma_{n}^{r}=\left(\boldsymbol{\Sigma}: \mathbb{N}^{r}: \mathbf{\Sigma}\right)^{1 / 2}, \quad \sigma_{t}^{r}=\left(\frac{1}{2} \boldsymbol{\Sigma}: \mathbb{T}^{r}: \mathbf{\Sigma}\right)^{1 / 2}$

The fourth-order operators $\mathbb{N}^{r}$ and $\mathbb{T}^{r}$ are both functions of the unit normal vector $\mathbf{n}^{r}$, and are, respectively, given by the following expressions:

$N_{i j k l}^{r}=n_{i}^{r} n_{j}^{r} n_{k}^{r} n_{l}^{r}$,

$T_{i j k l}^{r}=\frac{1}{2}\left(\delta_{i k} n_{j}^{r} n_{l}^{r}+\delta_{i l} n_{j}^{r} n_{k}^{r}+\delta_{j k} n_{i}^{r} n_{l}^{r}+\delta_{j l} n_{i}^{r} n_{k}^{r}-4 n_{i}^{r} n_{j}^{r} n_{k}^{r} n_{l}^{r}\right)$

In a similar way, the overall locked plastic energy can also be expressed in a discrete form:

$\Psi^{p}=\sum_{r=1}^{m} \rho^{r} \Psi^{p, r}\left(\gamma_{p}^{r}, \omega\left(\mathbf{n}^{r}\right)\right)$

The discrete thermodynamic forces associated with the plastic hardening variable $\gamma_{p}^{r}$ and damage variable $\omega\left(\mathbf{n}^{r}\right)$ are also defined for each family of microcracks, respectively, as follows:

$A^{r}=\frac{\partial \Psi^{p, r}}{\partial \gamma_{p}^{r}}, \quad F_{\omega}\left(\mathbf{n}^{r}\right)=-\frac{\partial \Psi}{\partial \omega\left(\mathbf{n}^{r}\right)}$

In the framework of irreversible thermodynamics, the formulation of the discrete model must be capable of determining the local plastic yield function, the plastic flow rule and the damage evolution law. Different forms of these functions have been proposed in previous work $[34,35]$. 


\subsection{Characterization of inherent anisotropy}

By adopting the Voigt notation, the constitutive relation for the general linear elasticity can be expressed in the 123 coordinate system (loading coordinate system):

$$
\left(\begin{array}{l}
\bar{\varepsilon}_{11} \\
\bar{\varepsilon}_{22} \\
\bar{\varepsilon}_{33} \\
2 \bar{\varepsilon}_{12} \\
2 \bar{\varepsilon}_{13} \\
2 \bar{\varepsilon}_{23}
\end{array}\right)=\left(\begin{array}{llllll}
S_{11} & S_{12} & S_{13} & S_{14} & S_{15} & S_{16} \\
S_{21} & S_{22} & S_{23} & S_{24} & S_{25} & S_{26} \\
S_{31} & S_{32} & S_{33} & S_{34} & S_{35} & S_{36} \\
S_{41} & S_{42} & S_{43} & S_{44} & S_{45} & S_{46} \\
S_{51} & S_{52} & S_{53} & S_{54} & S_{55} & S_{56} \\
S_{61} & S_{62} & S_{63} & S_{64} & S_{65} & S_{66} \\
& & & & &
\end{array}\right)\left(\begin{array}{c}
\sum_{11} \\
\sum_{22} \\
\sum_{33} \\
\sum_{12} \\
\sum_{13} \\
\sum_{23}
\end{array}\right)
$$

where $S_{i j}(i, j=1,2,3)$ is the compliance tensor of a $6 \times 6$ matrix. The compliance matrix can be described explicitly by describing the physical meaning of each element as a function of the elastic moduli, Poisson ratios, shear moduli and other technical constants of the material.

For the studied rock, this description shows an inherent transverse isotropy due to the presence of a set of bedding planes. By treating the studied rock as an orthotropic elastic material, another coordinate system, $x y z$ (also named as a material coordinate system) is set up, and the angle between the material coordinate system and loading coordinate system is defined as $\theta$ (see Fig. 3 ). The compliance matrix in the material coordinate system can be given by the following:

$S_{m n}^{\prime}=\left(\begin{array}{cccccc}\frac{1}{E_{x}} & \frac{v_{y x}}{E_{y}} & \frac{v_{z x}}{E_{z}} & & & \\ \frac{v_{x y}}{E_{x}} & \frac{1}{E_{y}} & \frac{v_{z y}}{E_{z}} & & & \\ \frac{v_{x z}}{E_{x}} & \frac{v_{y z}}{E_{y}} & \frac{1}{E_{z}} & & & \\ & & & \frac{1}{G_{x y}} & & \\ & & & & \frac{1}{G_{y z}} & \\ & & & & & \frac{1}{G_{z x}}\end{array}\right)$

with

$\frac{v_{m n}}{E_{m}}=\frac{v_{n m}}{E_{n}},(m, n=x, y, z)$

where $E_{x}, E_{y}$ and $E_{z}$ are the elastic moduli in the $x, y$ and $z$ directions; $G_{x y}, G_{y z}$ and $G_{z x}$ are the shear moduli in the $x y, y z$ and $z x$ planes; and $v_{x y}, v_{y z}$ and $v_{z x}$ are the Poisson ratios, respectively. Furthermore,

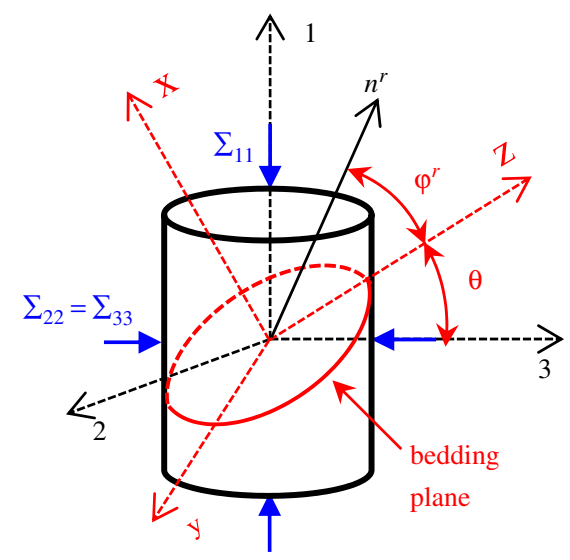

Fig. 3. Definition of two coordinate systems and the $r$ th family of microcracks. assuming that the plane $y z$ is isotropic, the studied rock is transversely isotropic and that the following relations can be obtained:

$E_{y}=E_{z}, \quad v_{x y}=v_{x z}, \quad v_{y z}=v_{z y}$

Using rotational transformation, the compliance tensor $S_{i j}$ in the loading coordinate system can be written as follows:

$S_{i j}=S_{m n}^{\prime} q_{m i} q_{n j}$

with

$q_{i j}=\left(\begin{array}{llllll}\cos ^{2} \theta & \sin ^{2} \theta & 0 & 0 & 0 & 2 \sin \theta \cos \theta \\ \sin ^{2} \theta & \cos ^{2} \theta & 0 & 0 & 0 & -2 \sin \theta \cos \theta \\ 0 & 0 & 1 & 0 & 0 & 0 \\ & & & & \cos & \\ & & & & \cos & \\ -\sin \theta \cos \theta & -\sin \cos \theta & 0 & & & -\sin ^{2} \theta \cos ^{2} \theta\end{array}\right)$

Therefore, by inserting the matrix of Eq. (16) into Eq. (15), it is possible to express the elastic constants (i.e., the elastic modulus or Poisson's ratio) of an inherently anisotropic material with a set of bedding planes in the loading coordinate system. After transferring the two-order compliance tensor $S_{i j}$ into a four-order compliance tensor $\mathbb{S}$, the initial elastic modulus tensor of the partially saturated materials without induced damage can be written as follows:

$\mathbb{C}^{0}\left(p_{c p}\right)=\mathbb{S}^{-1}\left(p_{c p}\right)$

Based on micromechanical analyses on anisotropic poroelastic materials [36-38], the Biot coefficients can be deduced from the elastic modulus tensor as follows:

$\alpha_{i j}\left(p_{c p}\right)=\delta_{i j}-\frac{C_{i j k k}^{0}\left(p_{c p}\right)}{3 K_{s}}$

where $K_{s}$ is the bulk modulus of the solid skeleton.

\subsection{Plastic modeling for inherently anisotropic materials under partially saturated conditions}

In partially saturated materials, the microcracks and pores are partially saturated with fluid and subjected to capillary pressure variation. The local plastic deformation and damage evolution are influenced by the variation of capillary pressure. Therefore, the local plastic yield criterion and potential and the damage criterion for dry materials should be considered in the effect of capillary pressure. More precisely, the plastic formulation and damage criterion are functions of not only the local shear and normal stresses $\sigma_{n}^{r}$ and $\sigma_{t}^{r}$ but also of the capillary pressure. Therefore, they should be used as independent variables in the formulation of the plastic yield function and potential. In practice, two different types of approaches can be identified for description of the capillary pressure effect on plastic deformation of rocks. The first is based on the extension of Biot's theory for saturated porous media to unsaturated media and consists of finding an equivalent interstitial pressure for the multiphase media as a function of the pore pressure and saturation degree of each phase. Using this equivalent interstitial pressure, it is possible to define effective stress tensors for poroelastic and poroplastic modeling. However, from the theoretical and experimental point of view, the validation of this concept is not fully proven in the theoretical and experimental frameworks, in particular for partially saturated porous media. Only partial validation from homogenization techniques can be found in $[39,40]$. In the second approach, the concept of net stress defined by $\Sigma^{\prime}=\Sigma+\alpha p_{g m}$ is introduced into the plastic constitutive equations of the unsaturated materials [11]. The capillary pressure is used 
as a complementary force variable, and plastic functions explicitly depend on the capillary pressure. This concept has been verified by a large body of test data taken from partially saturated soils and rocks [41]. This more physically based method is adopted in the present work for the description of the plastic deformation. It is assumed that the capillary pressure affects the normal stress, and we introduce the following effective normal stress $\bar{\sigma}_{n}^{r}$ for each family of microcracks:

$\bar{\sigma}_{n}^{r}=\sigma_{n}^{r}+\alpha:\left(\mathbf{n}^{r} \otimes \mathbf{n}^{r}\right) p_{g m}$

Based on previous work on the modeling of completely saturated material [42], a Coulomb-type plastic yield function is adopted here for frictional sliding along each family of partially saturated microcracks using the effective normal stress:

$f_{p}^{r}\left(\sigma_{n}^{r}, \sigma_{t}^{r}, \gamma_{p}^{r}, p_{c p}\right)=\sigma_{t}^{r}+\alpha_{p}^{r}\left(\gamma_{p}^{r}, p_{c p}\right)\left(m^{r} \bar{\sigma}_{n}^{r}-c^{r}\right)-R_{p}^{r} \leqslant 0$

$f_{p}^{r}\left(\sigma_{n}^{r}, \sigma_{t}^{r}, \gamma_{p}^{r}, p_{c p}\right)=\sigma_{t}^{r}+\alpha_{p}^{r}\left(\bar{\sigma}_{n}^{r}-c_{0}\right)-R_{p}^{r} \leqslant 0$

where $c^{r}$ and $m^{r}$ denote the cohesion and friction coefficients of the $r$ th family of microcracks of argillite. The function $\alpha_{p}^{r}\left(\gamma_{p}^{r}, p_{c p}\right)$ defines the plastic hardening law in the $r$ th family of partially saturated microcracks and is then written as a function of the generalized plastic shear strain $\gamma_{p}^{r}$ and capillary pressure $p_{c p}$. Some previous researches $[15,29,30,32,33]$ have been carried out to study the effect of capillary pressure on plastic behavior. The specific form of the relationship between the plastic hardening and the capillary pressure must be determined from experimental data, for example, from suction-controlled triaxial compression tests. Unfortunately, for the argillite studied here, only a small number of such data are available. A linear term $\left(1+a_{1} \frac{p_{c p}}{p_{0}}\right)$ proposed by Shao et al. [15] is adopted to describe the effect of capillary pressure on plastic behavior.

$\alpha_{p}^{r}\left(\gamma_{p}^{r}, p_{c p}\right)=\left(1+a_{1} \frac{p_{c p}}{p_{0}}\right) \frac{\gamma_{p}^{r}}{a_{2}+\gamma_{p}^{r}}$

where the parameter $a_{1}$ is introduced to describe the effect of capillary pressure on plastic hardening, and $p_{0}=1 \mathrm{MPa}$ is a unit pressure. The parameter $a_{2}$ controls the evolution rate of plastic hardening with a generalized plastic shear strain. When the capillary pressure is equal to zero and the argillite is completely saturated, the plastic yield function recovers to its general form [43].

According to previous investigations [35], the frictional sliding exhibits a softening behavior due to progressive destruction of the microcrack asperities. Therefore, the function $R_{p}^{r}$ is introduced to describe the softening behavior and is a function of the generalized plastic shear strain:

$R_{p}^{r}=H_{1} \gamma_{p}^{r} e^{-a_{3} \gamma_{p}^{r}}$

Two parameters, $H_{1}$ and $a_{3}$, determine the evolution kinetics of $R_{p}^{r}$.

Note that the two parameters $c^{r}$ and $m^{r}$ are dependent on the direction of the microcrack family and are affected by the orientation of bedding planes, such that they must be defined in terms of a spatial distribution function. Invoking previous investigations $[24,25,27]$, the following distribution functions are adopted:

$c^{r}=m_{1}^{c}+m_{2}^{c} \exp \left[\Omega_{0}^{c}\left(1-3 \cos ^{2} \varphi^{r}\right)\right]$

$m^{r}=m_{1}^{m}+m_{2}^{m} \exp \left[\Omega_{0}^{m}\left(1-3 \cos ^{2} \varphi^{r}\right)\right]$

where $m_{1,2}^{c}$ and $m_{1,2}^{m}$ are coefficients that are independent of direction, $\Omega_{0}^{c}$ and $\Omega_{0}^{m}$ are the projection of spatial distribution of $c^{r}$ and $m^{r}$ on the bedding plane, respectively, and $\varphi^{r}$ is the angle of the $r$ th family of microcracks with respect to the $z$-axis in the material coordinate system (see Fig. 1). The directional dependency of $c^{r}$ and $m^{r}$ can thus be described by selecting six coefficients: $m_{1}^{c}, m_{2}^{c}, \Omega_{0}^{c}$, $m_{1}^{m}, m_{2}^{m}$ and $\Omega_{0}^{m}$. These coefficients may be determined from a series of triaxial compression tests conducted on specimens with different inclinations of bedding planes at a completely saturated state.

The generalized plastic shear strain is used as the plastic hardening variable and is defined for each family of microcracks:

$\mathrm{d} \gamma_{p}^{r}=2\left(\mathrm{~d} \bar{\varepsilon}^{p, r}\right): \mathbb{T}^{r}:\left(\mathrm{d} \bar{\varepsilon}^{p, r}\right)=\mathrm{d} \boldsymbol{\gamma}^{r} \cdot \mathrm{d} \boldsymbol{\gamma}^{r}$

As mentioned above, the frictional sliding generates normal opening or closure of microcracks, which is the origin of macroscopic volumetric dilatancy and compaction. In the case of the associated flow rule, the normal strain in the microcracks cannot be correctly described. Therefore, a non-associated plastic flow rule is generally required and is given in the following form:

$g_{p}^{r}\left(\sigma_{t}^{r}, \sigma_{n}^{r}, \gamma_{p}^{r}, \omega^{r}\right)=\sigma_{t}^{r}+\left(1-\omega^{r}\right)\left(\alpha_{p}^{r}-\eta\right) \bar{\sigma}_{n}^{r}$

where the parameter $\eta$ defines the transition point from the compressibility zone $\left(\alpha_{p}^{r}<\eta\right)$ to the dilatancy zone $\left(\alpha_{p}^{r}>\eta\right)$.

The plastic flow rule and the loading-unloading condition are, respectively, described as follows:

$\mathrm{d} \bar{\varepsilon}^{p, r}=\mathrm{d} \lambda_{p}^{r} \frac{\partial g_{p}^{r}}{\partial \mathbf{\Sigma}}=\mathrm{d} \lambda_{p}^{r}\left(\frac{\mathbf{t}^{r} \otimes \mathbf{n}^{r}+\mathbf{n}^{r} \otimes \mathbf{t}^{r}}{2}+\eta_{p}^{r} \mathbf{n}^{r} \otimes \mathbf{n}^{r}\right)$

$\mathbf{t}^{r}=\frac{1}{\sigma_{t}^{r}} \boldsymbol{\Sigma} \cdot \mathbf{n}^{r} \cdot\left(\boldsymbol{\delta}-\mathbf{n}^{r} \otimes \mathbf{n}^{r}\right)$

$f_{p}^{r}\left(\bar{\sigma}_{n}^{r}, \sigma_{t}^{r}, \gamma_{p}^{r}\right)=0, \quad \mathrm{~d} \lambda_{p}^{r} \geqslant 0, f_{p}^{r} \cdot \mathrm{d} \lambda_{p}^{r}=0$

The vector $\mathbf{t}^{r}$ defines the direction of plastic shearing inside the microcrack plane. According to Eq. (5), the plastic strain increment can also be written as follows:

$\mathrm{d} \bar{\epsilon}^{p, r}=\mathrm{d} \beta^{r} \mathbf{n}^{r} \otimes \mathbf{n}^{r}+\frac{1}{2}\left(\mathrm{~d} \boldsymbol{\gamma}^{r} \otimes \mathbf{n}^{r}+\mathbf{n}^{r} \otimes \mathrm{d} \boldsymbol{\gamma}^{r}\right)$

with

$\mathrm{d} \gamma^{r}=d \lambda_{p}^{r} \mathbf{t}^{r}, \quad d \beta^{r}=\mathrm{d} \lambda_{p}^{r} \eta_{p}^{r}$

The plastic multiplier $\mathrm{d} \lambda_{p}^{r}$ is determined from the plastic consistency condition $\dot{f}_{p}^{r}=0$ for each family of microcracks. Unlike classic plastic models with a single yield surface, the consistency condition should be verified simultaneously for all families of microcracks. This means that the plastic flow is coupled among the different families of microcracks.

Invoking the incremental form of the constitutive relations in a stationary damage state, the following formula can be written:

$\dot{\boldsymbol{\Sigma}}=\mathbb{C}(\omega(\mathbf{n})):\left(\dot{\bar{\varepsilon}}-\sum_{r=1}^{m} \rho^{r} \dot{\bar{\varepsilon}}^{p, r}\right)$

Then, the plastic consistency condition can be written as follows:

$\dot{f}_{p}^{r}=\frac{\partial f_{p}^{r}}{\partial \mathbf{\Sigma}}: \mathbb{C}(\omega(\mathbf{n})):\left(\dot{\bar{\varepsilon}}-\sum_{k=1}^{m} \rho^{k} \mathrm{~d} \lambda_{p}^{k} \frac{\partial g_{p}^{k}}{\partial \boldsymbol{\Sigma}}\right)+\frac{\partial f_{p}^{r}}{\partial \gamma_{p}^{r}} \dot{\gamma}_{p}^{r}=0$

We then introduce the following interaction matrix $\left[\mathbf{M}^{p}\right]_{m \times m}$ :

$M_{I J}^{p}=\rho^{I} \frac{\partial f_{p}^{I}}{\partial \boldsymbol{\Sigma}}: \mathbb{C}(\omega(\mathbf{n})): \frac{\partial g_{p}^{I}}{\partial \boldsymbol{\Sigma}}-\frac{\partial f_{p}^{I}}{\partial \gamma_{p}^{I}} \frac{\partial g_{p}^{I}}{\partial \sigma_{t}^{I}} \delta_{I J}$

The determination of the plastic multipliers requires the solution of the following system of equations:

$\left[\mathbf{M}^{p}\right]\left\{\mathrm{d} \lambda_{p}\right\}=\left\{\frac{\partial f_{p}}{\partial \mathbf{E}}\right\}: \dot{\bar{\varepsilon}},\left\{\mathrm{d} \lambda_{p}\right\}=\left[\mathbf{M}^{p}\right]^{-1}\left\{\frac{\partial f_{p}}{\partial \mathbf{E}}\right\}: \dot{\bar{\varepsilon}}$

The tangent elastoplastic operator takes the following form:

$\left\{\begin{array}{l}\dot{\boldsymbol{\Sigma}}=\mathbb{C}^{e p}\left(\gamma_{p}^{r}, \omega(\mathbf{n})\right): \dot{\bar{\varepsilon}} \\ \mathbb{C}^{e p}\left(\gamma_{p}^{r}, \omega(\mathbf{n})\right)=\mathbb{C}(\omega(\mathbf{n}))-\sum_{r=1}^{m} \rho^{r} d \lambda_{p}^{r} \frac{\partial g_{p}^{r}}{\partial \bar{\varepsilon}}\end{array}\right.$ 
The derivatives of the yield function and plastic potential with respect to the overall strain are given by the following:

$$
\begin{aligned}
& \frac{\partial f_{p}^{I}}{\partial \bar{\varepsilon}}=\mathbb{C}(\omega(\mathbf{n})):\left[\frac{1}{2}\left(\mathbf{t}^{I} \otimes \mathbf{n}^{I}+\mathbf{n}^{I} \otimes \mathbf{t}^{I}\right)+\alpha_{p}^{I} \mathbf{n}^{I} \otimes \mathbf{n}^{I}\right] \\
& \frac{\partial g_{p}^{J}}{\partial \bar{\varepsilon}}=\mathbb{C}(\omega(\mathbf{n})):\left[\frac{1}{2}\left(\mathbf{t}^{J} \otimes \mathbf{n}^{J}+\mathbf{n}^{J} \otimes \mathbf{t}^{J}\right)+\eta_{p}^{J} \mathbf{n}^{J} \otimes \mathbf{n}^{J}\right]
\end{aligned}
$$

\subsection{Characterization of damage evolution for partially saturated materials}

The material damage is characterized by the distribution of microcracks in various orientations. According to the discrete thermodynamic approach used here, a scalar damage variable is defined for each family of microcracks that physically represents the extent of the microcracks. The evolution of damage is then associated with the growth of the microcracks. It is important to note that even if the damage state of each family of microcracks is defined by a scalar variable, the overall distribution of damage is not isotropic in nature. This observation is due to the fact the damage state is not uniform for all families of microcracks. Therefore, the scalar damage variable is also orientation-dependent. As a consequence, in addition to the inherent anisotropy, there is an induced anisotropy in material properties due to the oriented distribution of microcracks.

To determine the effective elastic stiffness of the initially anisotropic material, the customarily used assumption of "microisotropy" is adopted. It can be argued that the solid matrix of the rock is isotropic at the microscopic (pore and grain) level, and the macroscopic material anisotropy is of structural origin, mainly resulting from the oriented arrangement of fissures and bedding planes. Letting $k^{0}$ and $\mu^{0}$ be the initial bulk and shear moduli of the solid matrix, respectively, the induced damage mainly affects the shear modulus of the material according to mechanical analysis. Therefore, the following relations are adopted for the determination of the effective elastic properties of the induced damage material:

$k(\omega(\mathbf{n}))=k^{0}, \quad \mu(\omega(\mathbf{n}))=(1-\omega(\mathbf{n})) \mu^{0}$

Based on previous work $[34,35]$ on the effective elastic stiffness tensor of the initially isotropic material, the initially anisotropic material can be described in the following form:

$\mathbb{C}(\omega(\mathbf{n}))=\mathbb{C}^{0}-2 \mu^{0} \sum_{r=1}^{m} \rho^{r} \omega^{r} \mathbb{T}^{r}$

where $\mathbb{C}^{0}$ is the initial elastic stiffness tensor of the undamaged material, which has been defined in Eq. (17), and $\omega^{r}$ is defined by $\omega^{r}=\omega\left(\mathbf{n}^{r}\right), r=1 \ldots m$ and plays a role in replacement of the continuous distribution function by a discrete distribution of damage density for a limited number of orientations. Lastly, $\rho^{r}$ is the weight coefficient for the $r$ th family of microcracks.

The thermodynamic force conjugated with the discrete damage variable related to the $r$ th family of microcracks is given by the following:

$F^{\omega^{r}}=-\frac{\partial \Psi}{\partial \omega^{r}}=\mu^{0} \rho^{r}\left(\bar{\varepsilon}-\bar{\varepsilon}^{p}\right): \mathbb{T}^{r}:\left(\bar{\varepsilon}-\bar{\varepsilon}^{p}\right)$

Further, the non-negative condition of intrinsic dissipation must be satisfied for the damage evolution and plastic flow in each family of microcracks:

$\Sigma: \dot{\bar{\varepsilon}}^{p, r}+F^{\omega^{r}} \dot{\omega}^{r} \geqslant 0$

If we neglect the interaction among different families of microcracks in terms of dissipation, the damage dissipation in each family occurs in an independent manner. Thus, the overall positive property of intrinsic dissipation can be written as follows:

$\boldsymbol{\Sigma}: \dot{\bar{\varepsilon}}^{p}+\sum_{r=1}^{m} \rho^{r} F^{\omega^{r}} \dot{\omega}^{r} \geqslant 0$

In the framework of the thermodynamics of irreversible processes, the damage evolution in each family of microcracks is determined by the definition of a suitable criterion that is a scalar-valued function of the thermodynamic force defined above. However, with such a theoretical approach, it is generally difficult to identify the damage criterion from experimental data and to realize numerical implementation of the damage model. A more pragmatic approach is used here for the sake of simplicity and based on physical considerations. It is assumed that the damage is essentially generated by plastic shear sliding along the microcrack surfaces. Therefore, we consider that the local plastic shear strain is the driving force for the damage evolution in each family of microcracks. Inspired by various damage criteria in the literature (e.g., [44] for concrete), the following exponential function is proposed:

$f_{\omega}^{r}=\omega^{r}-\left(1-e^{-a_{4} \gamma_{p}^{r}}\right) \leqslant 0$

where $a_{4}$ is a parameter used to control the kinetics of damage evolution and is independent of the capillary pressure. However, the generalized plastic shear strain $\gamma_{p}^{r}$ is deduced from the plastic flow, which is a function of capillary pressure. Therefore, the damage evolution is also affected by the capillary pressure in partially saturated materials.

\section{Calibration procedure of model parameters}

The proposed model includes five independent elastic parameters $\left(E_{x}, E_{y}, v_{x y}, v_{y z}\right.$ and $\left.G_{x y}\right)$, the bulk modulus of the solid skeleton $\left(K_{s}\right)$, seven parameters for inherent anisotropic strength $\left(a_{1}, m_{1}^{c}, m_{2}^{c}, \Omega_{0}^{c}, m_{1}^{m}, m_{2}^{m}\right.$ and $\left.\Omega_{0}^{m}\right)$, four parameters for plastic evolution $\left(a_{2}, a_{3}, H_{1}\right.$ and $\left.\eta\right)$ and the parameters for damage evolution $\left(a_{4}\right)$. In order to identify these parameters, the calibration procedure is carried out in two steps:

(i) Under saturated condition, the capillary pressure in samples can be assumed identical to zero and thus has no effect on the mechanical behavior. Therefore, the saturated condition can be viewed as a referential state. The triaxial compressions tests with loading-unloading cycles on saturated samples are firstly used to calibrate the model parameters under saturated condition.

(ii) The evolutions of certain parameters related to capillary pressure are consequently determined from triaxial compression tests on samples under different levels of relative humidity.

\subsection{Calibration under saturated condition}

Because the argillite sample can be viewed as transversely isotropic in its material coordinate system, its initial elastic compliance under saturated condition in the loading coordinate system can be characterized by five independent elastic parameters $\left(E_{x}\right.$, $E_{y}, v_{x y}, v_{y z}$ and $G_{x y}$ ) and a transformation angle $\theta$. The two Young's moduli $E_{x}$ and $E_{y}$ corresponding to two structural directions $x$ and $y$ (or $z$ ) are obtained from tests on saturated samples performed at $\theta=0^{\circ}$ and $\theta=90^{\circ}$, respectively, by measuring the axial strain during the unloading path. Similarly, the Poisson ratio $v_{x y}$ is determined from tests at $\theta=0^{\circ}\left(v_{x y}=-\Delta \varepsilon_{y} / \Delta \varepsilon_{x}\right)$, while $v_{y z}$ is obtained from tests at $\theta=90^{\circ}\left(v_{y z}=-\Delta \varepsilon_{z} / \Delta \varepsilon_{y}\right)$. The shear modulus $G_{x y}$ can be obtained from any tests performed in an out-of-axis orientation. 
By performing an unjacketed hydrostatic compression test in which the interstitial pressure increment is equal to the confining stress increment, it is possible to identify the bulk modulus of the solid skeleton $K_{s}$.

The next issue is that of identification of the parameters of inherent anisotropic strength appearing in the plastic yield criterion (20). The cohesion $c$ and friction $m$ parameters at saturated state can be defined from triaxial tests conducted on specimens with different inclinations of the bedding planes under saturated condition [45]. According to Eqs. (23) and (24), $c$ and $m$ increase exponentially with $\varphi^{r}$. If the values of $c$ and $m$ for $\varphi^{r}=0$ and $\varphi^{r}=\varphi^{*}$ are available, $m_{1,2}^{c}$ and $m_{1,2}^{m}$ can be expressed in terms of $\Omega_{0}^{c}$ and $\Omega_{0}^{m}$ as follows:

$$
\begin{aligned}
& m_{1}^{c}=\frac{c_{\varphi^{*}} \exp \left(-2 \Omega_{0}^{c}\right)-c_{0} \exp \left(\lambda \Omega_{0}^{c}\right)}{\exp \left(-2 \Omega_{0}^{c}\right)-\exp \left(\lambda \Omega_{0}^{c}\right)} \\
& m_{2}^{c}=\frac{c_{0}-c_{\varphi^{*}}}{\exp \left(-2 \Omega_{0}^{c}\right)-\exp \left(\lambda \Omega_{0}^{c}\right)} \\
& m_{1}^{m}=\frac{m_{\varphi^{*}} \exp \left(-2 \Omega_{0}^{m}\right)-m_{0} \exp \left(\lambda \Omega_{0}^{m}\right)}{\exp \left(-2 \Omega_{0}^{m}\right)-\exp \left(\lambda \Omega_{0}^{m}\right)} \\
& m_{2}^{m}=\frac{m_{0}-m_{\varphi^{*}}}{\exp \left(-2 \Omega_{0}^{m}\right)-\exp \left(\lambda \Omega_{0}^{m}\right)}
\end{aligned}
$$

where $\lambda=\left(1-3 \cos ^{2} \varphi^{*}\right)$. In this work, the triaxial tests are conducted on specimens with two inclinations of bedding planes of $\theta=0^{\circ}$ and $\theta=60^{\circ}$, which correspond to shear failure and sliding failure and are used to determine the directional distribution of $c$ and $m$, respectively. For the specimens at $\theta=0^{\circ}$, the axial loading direction is perpendicular to the bedding planes, and the failure is due to the shear band in the argillite matrix; the fracture angle may be assumed as equal to $70^{\circ}$ according to experimental observation [23]. Following this assumption, the angle $\varphi^{*}$ in Eqs. (44)-(47) can be identified as $\varphi^{*}=70^{\circ}$, and the value of the cohesion $c$ and friction $m$ parameters obtained from the specimen at $\theta=0^{\circ}$ can be identified as $c_{70}$ and $m_{70}$, respectively. Similarly, for the specimens at $\theta=60^{\circ}$, the failure generally takes place because of the sliding planes; thus, the fracture angle is nearly equal to $\theta$. Therefore, the angle $\varphi^{0}$ with respect to the bedding planes in Eqs. (44)-(47) can be identified as $\varphi^{0}=0^{\circ}$, and the value of the cohesion $c$ and friction $m$ parameters obtained from this specimen at $\theta=60^{\circ}$ can be identified as $c_{0}$ and $m_{0}$, respectively. The directional distributions of $c$ and $m$ for saturated samples are determined by employing the above values and conducting a trial-and-error study of $\Omega_{0}^{c}$ and $\Omega_{0}^{m}$ [45].

Due to the complication of plastic yield and potential function, the parameters for describing plastic evolution $\left(a_{2}, a_{3}, H_{1}\right.$ and $\left.\eta\right)$ and the parameters for damage evolution $\left(a_{4}\right)$ are determined in two steps: a preliminarily value determined from the physical analysis and verification by fitting the experimental curves with the help of the trial-and-error procedure. The parameter $a_{2}$ characterizing the plastic hardening rate is determined by plotting $\alpha_{p}^{r}$ vs. the generalized plastic shear strain $\gamma_{p}^{r}$ from the nonlinear portion between the elastic limit and the peak stress obtained in the triaxial compression tests. By identifying the stress point where the volumetric strain rate is close to zero on the stress-strain curves, the parameter $\eta$ can be obtained. Two parameters, $a_{3}$ and $H_{1}$, which control the material softening, are identified from post peak stress-strain curves. During a triaxial compression test, selected loading-reloading cycles are performed at different stress levels (damage levels) and the effective modulus at each cycle can be measured from the stress-strain curves. By comparing the effective modulus and the initial one, the value of damage at each cycle can be determined and the damage-plastic shear strain curve can be plotted, the evolution kinetics of damage is thus known and a preliminary value of parameter $a_{4}$ is obtained. These values are fatherly verified by fitting the stress-strain curves of triaxial compression tests with cyclic loading on saturated samples.

\subsection{Calibration under partially saturated condition}

After the calibration of model parameters under saturated condition, the five independent elastic parameters $\left(E_{x}, E_{y}, v_{x y}, v_{y z}\right.$ and $G_{x y}$ ) and the parameters for describing the effect of capillary pressure on plastic hardening $\left(a_{1}\right)$, which are related to capillary pressure, should be consequently determined from triaxial compression tests on samples under different levels of relative humidity.

Based on the previous experimental data from Meuse/HauteMarne argillite [10], the Poisson ratios $v_{x y}$ and $v_{y z}$ change very little with the evolution of relative humidity, and their values at the studied relative humilities are assumed to be identical to that of the completely saturated state in this work. For the parameters $E_{x}, E_{y}$ and $G_{x y}$, we propose a linear relationship by fitting the experimental data at different relative humidity written as follows:

$X\left(p_{c p}\right)=X_{0}\left(1+b_{X} \frac{p_{c p}}{p_{0}}\right)$

where $X\left(p_{c p}\right)$ and $X_{0}$ represent $E_{x}, E_{y}$ and $G_{x y}$ at a given capillary pressure and zero capillary pressure (completely saturated state), and $p_{0}=1 \mathrm{MPa}$ is a unit pressure. The parameter $b_{X}$ is introduced to describe the effect of the capillary pressure and can be determined by fitting the evolution of the elastic parameters at different relative humilities.

For the parameter $a_{1}$, the trial-and-error procedure is adopted. We can firstly plot failure curves at different capillary pressure from triaxial compression tests with different levels of relative humidity, then the value of $a_{1}$ is preliminarily determined by fitting the relation between failure curves and capillary pressure. The value of $a_{1}$ is consequently verified by fitting the stress-strain curves of triaxial compression tests on samples with different levels of relative humidity.

\section{Numerical simulations}

In this section, the proposed model is first applied to describe the basic mechanical behavior of inherently anisotropic argillite with natural water content. After validation of the proposed model under the natural water content condition, the influence of water content on the mechanical behavior is also simulated for argillite samples with normal and parallel bedding planes.

For the simulation tests, a numerical implementation algorithm is developed for local integration of the discrete plastic damage model. Note that each test is assumed as performed on a representative elementary volume of material, which corresponds to a material point in structural analysis. However, the numerical modeling of stress and strain distributions in structures is not of concern in this paper. The local implementation (Gaussian point level) of the discrete plastic damage model is performed within the general framework of operator-split algorithms for nonlinear constitutive models. Inspired by the previous work in [34,35], the general outline of the integration algorithm for the $k$ th loading step can be summarized as follows:

(i) At the beginning of the $k$ th step, the following quantities are known: $\Sigma_{k-1}, \bar{\varepsilon}_{k-1}, \omega_{k-1}^{r}, \gamma_{k-1}^{r}, \beta_{k-1}^{r}$ and $\gamma_{k-1}^{p, r}$; calculate the trial elastic part of the total strain.

(ii) Set $j=1$ and start the iterative loop.

(iii) Given an incremental total strain $\Delta \bar{\varepsilon}_{k}$, perform an elastic prediction of stresses as follows: $\bar{\varepsilon}_{k, j}^{e}=\bar{\varepsilon}_{k, j-1}^{e}+\Delta \bar{\varepsilon}_{k}, \Sigma_{k, j}=$ $\left(\omega_{k, j-1}^{r}\right): \bar{\varepsilon}_{k, j}^{e}$ with $\bar{\varepsilon}_{k, 0}^{e}=\bar{\varepsilon}_{k-1}^{e}$ and $\omega_{k, 0}^{r}=\omega_{k-1}^{r}$.

(iv) Check the plastic yield condition $f_{j-1}^{p, r} \leqslant 0$ in the absence of damage evolution and determine the plastic multiplier if plastic flow occurs. 
Table 1

Representative values of model parameters for Tournemire argillite with natural water content.

\begin{tabular}{ll}
\hline Parameters & Values \\
\hline Elastic properties & $E_{x}=10200 \mathrm{MPa}, E_{y}=30500 \mathrm{MPa}, v_{x y}=0.12$, \\
& $v_{y z}=0.14, G_{x y}=4000 \mathrm{MPa}$ \\
Inherent anisotropic strength & $m_{1}^{c}=22 \mathrm{MPa}, m_{2}^{c}=5.5 \mathrm{MPa}, \Omega_{0}^{c}=-0.5$, \\
& $m_{1}^{m}=0.5, m_{2}^{m}=0.35, \Omega_{0}^{m}=-0.5$ \\
Plastic evolution & $a_{2}=0.005, a_{3}=30, H_{1}=354 \mathrm{MPa}, \eta=0.45$ \\
Damage criterion & $a_{4}=3$ \\
\hline
\end{tabular}

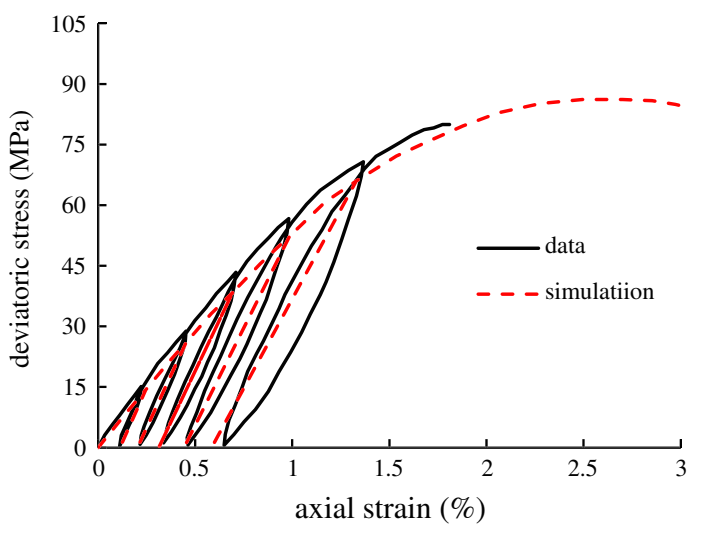

Fig. 4. Verification of model parameters by triaxial compression test with cyclic loading under confining stress of $30 \mathrm{MPa}$ on Tournemire argillite with normal bedding planes and natural water content.

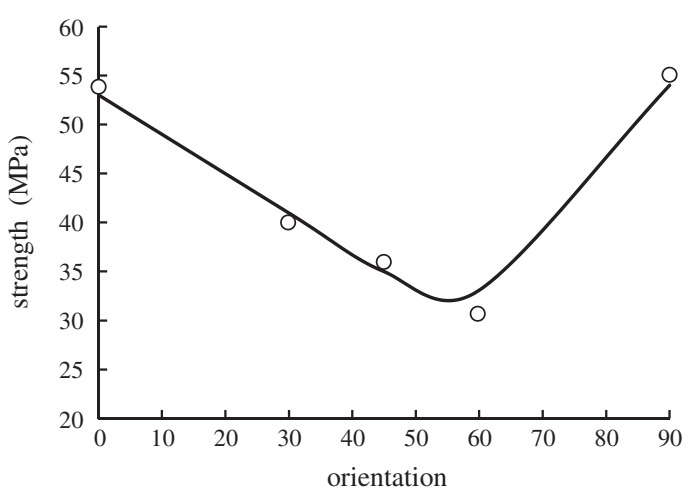

Fig. 5. Numerical simulation of strength as a function of the orientation of bedding planes with a confining stress of $5 \mathrm{MPa}$.

(v) Calculate $\bar{\gamma}_{j}^{p}$, then check the damage evolution $f^{\omega, r} \leqslant 0$ and determine the updated damage state.

(vi) If $\omega_{k, j}^{r}-\omega_{k, j-1}^{r}>e$ ( $e$ is a small positive tolerance coefficient), then $j=j+1$, go to (iii); else exit from the current iterative loop and go to (vii).

(vii) Calculate the updated values of quantities: $\Sigma_{k}=\Sigma_{k, j}, \omega_{k}^{r}=$ $\omega_{k, j}^{r}, \gamma_{k}^{r}=\gamma_{k, j}^{r}, \beta_{k}^{r}=\beta_{k, j}^{r}$ and $\gamma_{k}^{p, r}=\gamma_{k, j}^{p, r}$.

\subsection{Mechanical behavior of Tournemire argillite with natural water} content

In this section, we consider triaxial compression tests performed on Tournemire argillite with natural water content. As mentioned above, at natural water content levels, the Tournemire argillite is nearly completely saturated; we thus assume that the capillary pressure is identical to zero. Therefore, the model parameters can be identified by the calibration procedure in Section 4.2.

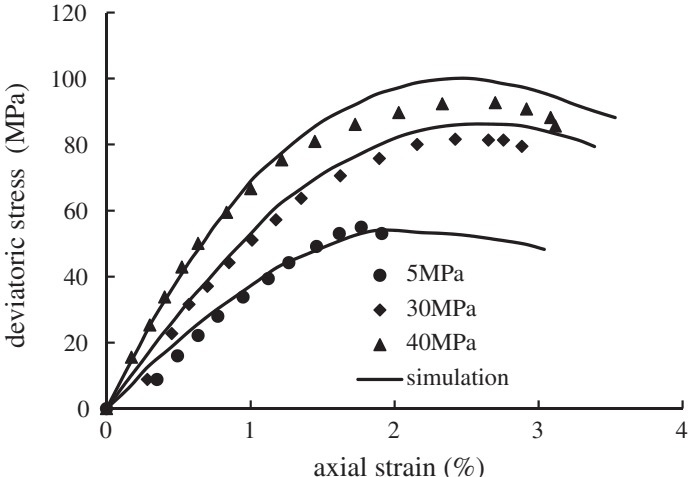

(a) $\theta=0^{\circ}$

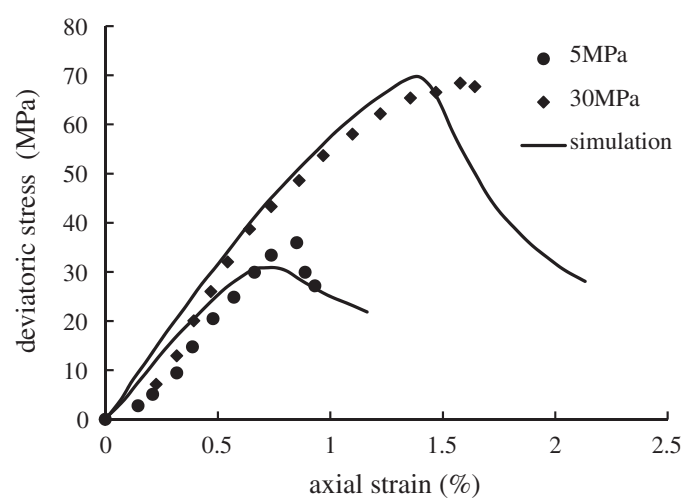

(b) $\theta=45^{\circ}$

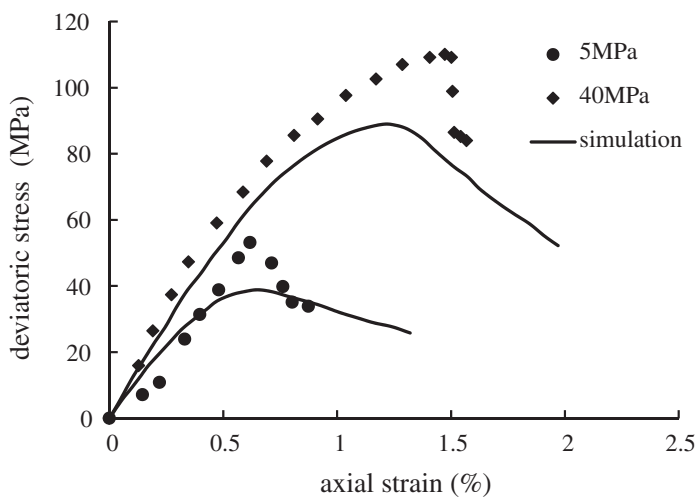

(c) $\theta=90^{\circ}$

Fig. 6. Numerical simulations of tri-axial tests of natural samples with different orientations of bedding planes: (a) $\theta=0^{\circ}$, (b) $\theta=45^{\circ}$ and (c) $\theta=90^{\circ}$.

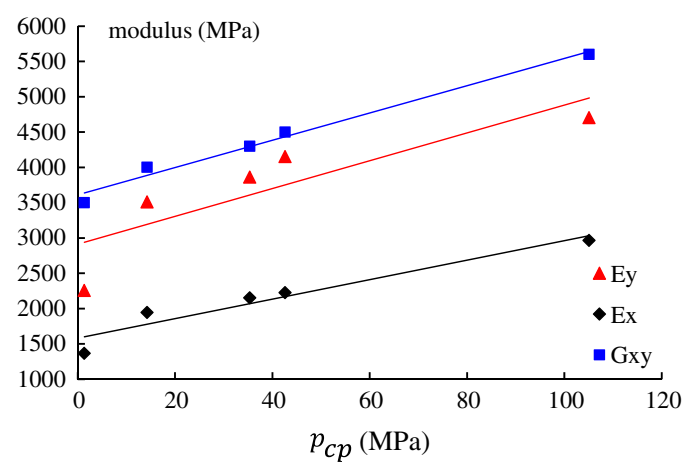

Fig. 7. Fitting of the evolution of elastic parameters at different capillary pressures 
Table 2

Representative values of model parameters for Meuse/Haute-Marne argillite under different levels of relative humidities.

\begin{tabular}{ll}
\hline Parameters & Values \\
\hline Inherent anisotropic strength & $m_{1}^{c}=22 \mathrm{MPa}, m_{2}^{c}=5.5 \mathrm{MPa}, \Omega_{0}^{c}=-0.5$, \\
& $m_{1}^{m}=0.5, m_{2}^{m}=0.35, \Omega_{0}^{m}=-0.5$ \\
& $a_{1}=0.014, a_{2}=0.005, a_{3}=30$, \\
Plastic evolution & $H_{1}=354 \mathrm{MPa}, \eta=0.45$ \\
Damage criterion & $a_{4}=3$ \\
\hline
\end{tabular}

The typical values of the model parameters for Tournemire argillite with natural water content are given in Table 1.

As mentioned above, the preliminary values of model parameters are estimated by physical analysis and the trial-and-error procedure is adopted for the verification the model parameters. Therefore, a triaxial compression test with cyclic loading under confining stress of $30 \mathrm{MPa}$ on Tournemire argillite with normal bedding planes and natural water content is firstly simulated in order to verify the model parameters and numerical result is presented in Fig. 4. It shows that the proposed model can describe the main mechanical mechanical behavior, such as nonlinear strain-stress curves, degradation of effective modulus, and accumulated plastic deformation. However, the hysteretic loops in the cyclic curves cannot be modeled in the present model and may be simulated by taking the unilateral effect of microcracks into account in the further work.

Fig. 5 shows the numerical simulation of strength as a function of the bedding planes in the triaxial compression test with a confining stress of $5 \mathrm{MPa}$. We find that the predicted strength is in

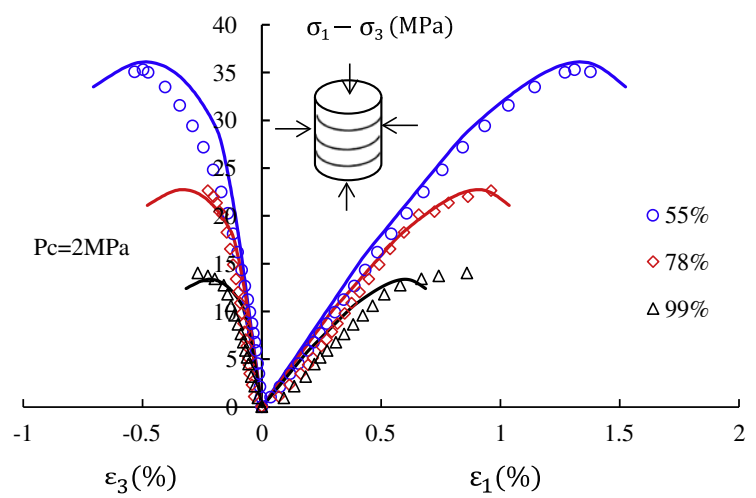

(a) Stress-strain curves with confining stress of $2 \mathrm{MPa}$

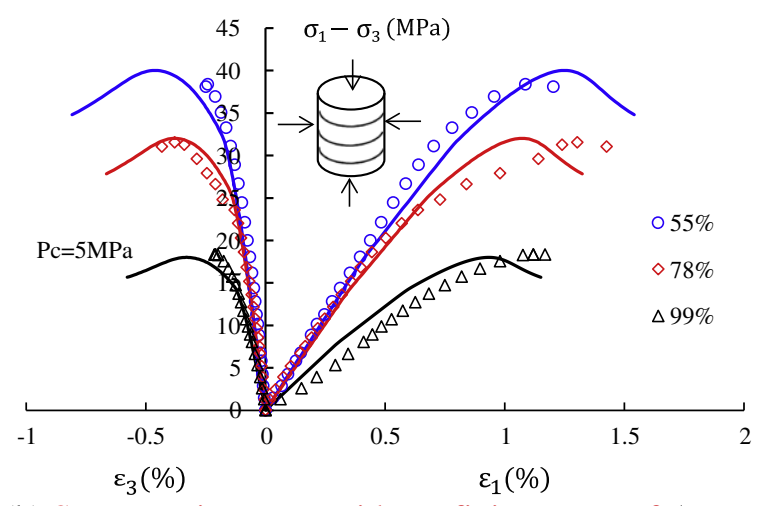

(b) Stress-strain curves with confining stress of $5 \mathrm{MPa}$

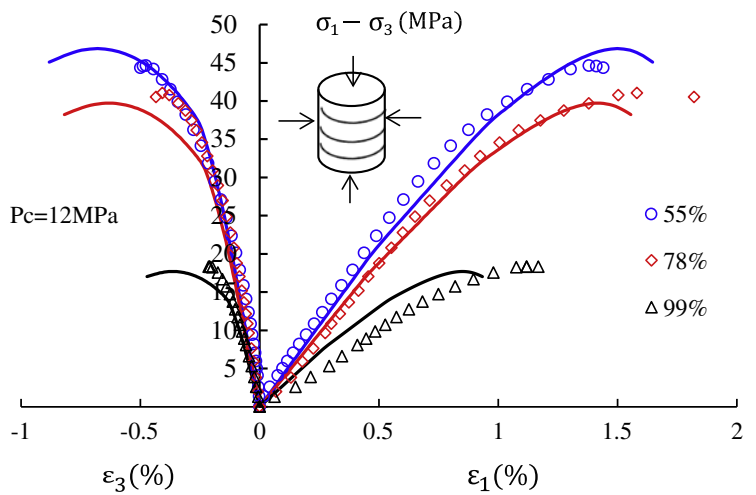

(c) Stress-strain curves with confining stress of $12 \mathrm{MPa}$

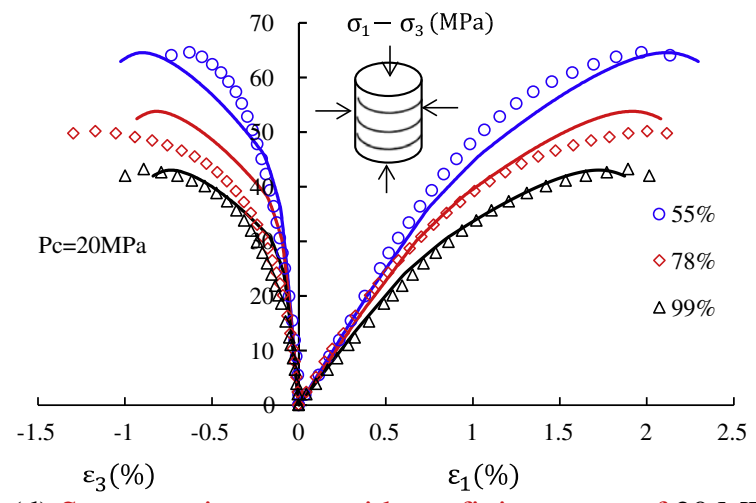

(d) Stress-strain curves with confining stress of $20 \mathrm{MPa}$

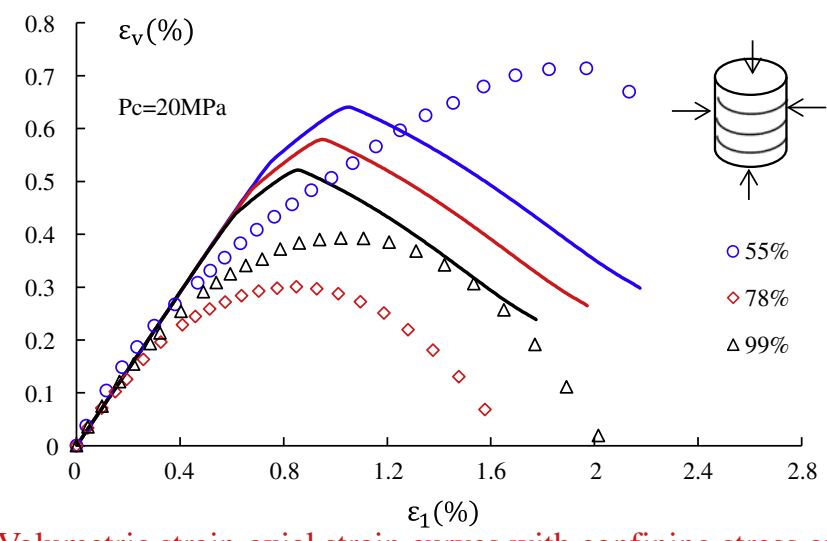

(e) Volumetric strain-axial strain curves with confining stress of $20 \mathrm{MPa}$

Fig. 8. Simulation of tri-axial compression tests under different levels of relative humidity with vertical bedding planes. 
good agreement with the experimental data; the proposed model is able to describe the strength dependency in the orientation of bedding planes.

Fig. 6a shows the deviatoric stress against the axial deformation of samples with normal bedding planes, $\theta=0^{\circ}$, tested at confining pressures ranging from 5 to $40 \mathrm{MPa}$. It is evident that the ultimate strength is significantly affected by the confining pressure. The strain-softening response, which is associated with strain localization for argillite and typically occurs in the range of low confining pressures, can also be well described. Fig. $6 \mathrm{~b}$ shows the deviatoric stress plotted against the axial deformation of samples with bedding planes inclined at $\theta=45^{\circ}$. The axial strength is significantly lower compared to that corresponding to $\theta=0^{\circ}$ in Fig. 6a. Again, the numerical results are consistent with the experimental evidence. Fig. $6 c$ presents the same characteristics for samples at $\theta=90^{\circ}$, i.e., when the load is parallel to the direction of the bedding planes. General observations are similar in that the strength increases in relation to samples tested at $\theta=90^{\circ}$, while the dilatancy effects become even more pronounced.

Overall, in the case of confining stress of $40 \mathrm{MPa}$ in Fig. 6a and c, the deviatoric peak stress is overestimated for $\theta=0^{\circ}$ but underestimated for $\theta=90^{\circ}$. In addition, the experimental results show a lower deviatoric peak stress for $\theta=0^{\circ}$ than the one for $\theta=90^{\circ}$, while the simulations show the opposite tendency. This disadvantage related to strength anisotropy may be attributed to the ignoring of the interactions between different families of microcracks. Near peak stress, the density of microcracks is increased at a great rate, this results in the augmentation of the interactions between

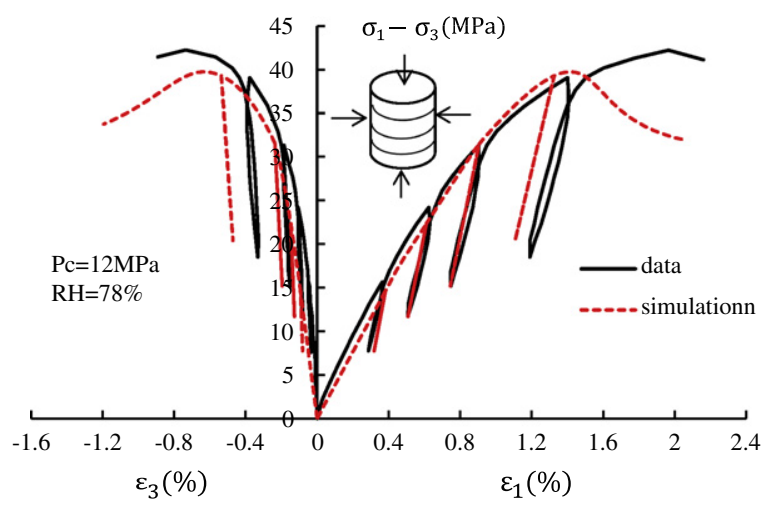

(a) Stress-strain curves with cyclic loading under confining stress of $12 \mathrm{MPa}$

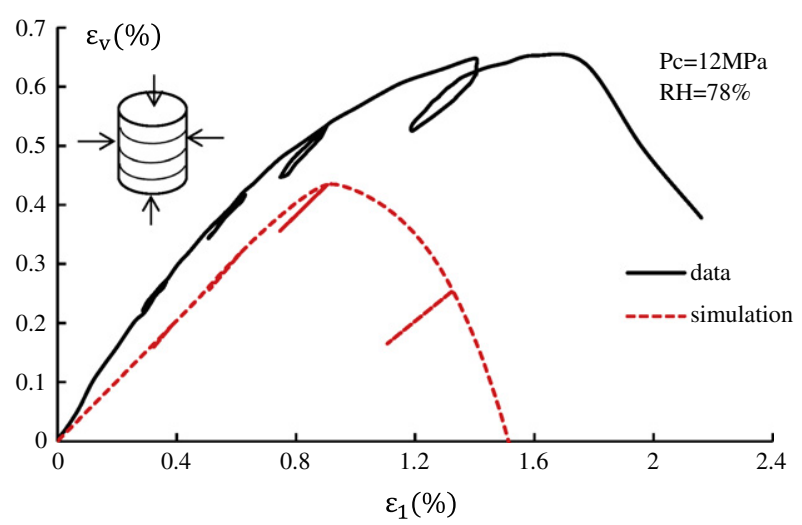

(b) Volumetric strain-axial strain curves with cyclic loading under confining stress of $12 \mathrm{MPa}$

Fig. 9. Simulation of triaxial compression tests with cyclic loading under different levels of relative humidity with vertical bedding planes. different families of microcracks, which are ignored in the present model. The other homogenization methods, such as self-consistent scheme, may be used to consider the interactions between different families of microcracks in the further study.

\subsection{Mechanical behavior of Meuse/Haute-Marne argillite with different water content}

Next, we consider compression tests performed on Meuse/ Haute-Marne argillite with normal and parallel bedding planes under different levels of relative humidity.

As mentioned in Section 4.2, the experimental results of Meuse/ Haute-Marne argillite with zero capillary pressure (completely saturated state) are used as a referential state and to determine the model parameters, which are independent of the capillary pressure. For the parameter $b_{X}$, which is introduced to describe the effect of the capillary pressure on the elastic parameters, is determined by fitting the evolution of the elastic parameters at different relative humilities according to experimental results [10]. Fig. 7 shows the fitting curves of elastic parameters-capillary pressure. The value of $a_{1}$ is determined by plotting the plastic yield surfaces and verified by the strain-stress curves from the compression tests at different relative humidities. Because of the low permeability of argillite, the unjacketed hydrostatic compression test is usually not practical. In this study, the modulus of the solid skeleton of argillite can be obtained as $K_{s}=35460 \mathrm{MPa}$ using a loading path consisting of successive two-step incremental loadings and the drained hydrostatic stress loading $\left(\Delta \sigma_{1}=\Delta \sigma_{2}=\Delta \sigma_{3}=\Delta \omega\right)$ with constant pore pressure $(\Delta p=0)$ and the pore pressure loading $(\Delta p=\Delta \omega)$ with constant hydrostatic stress $\left(\Delta \sigma_{1}=\Delta \sigma_{2}=\Delta \sigma_{3}=0\right)$.

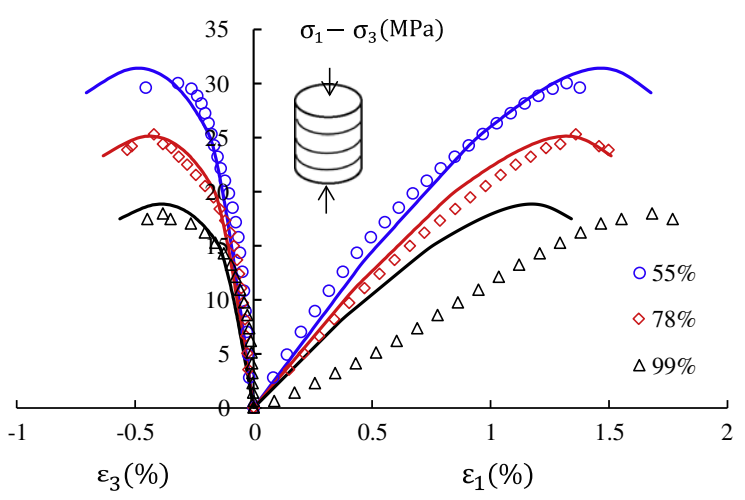

(a) Vertical bedding planes

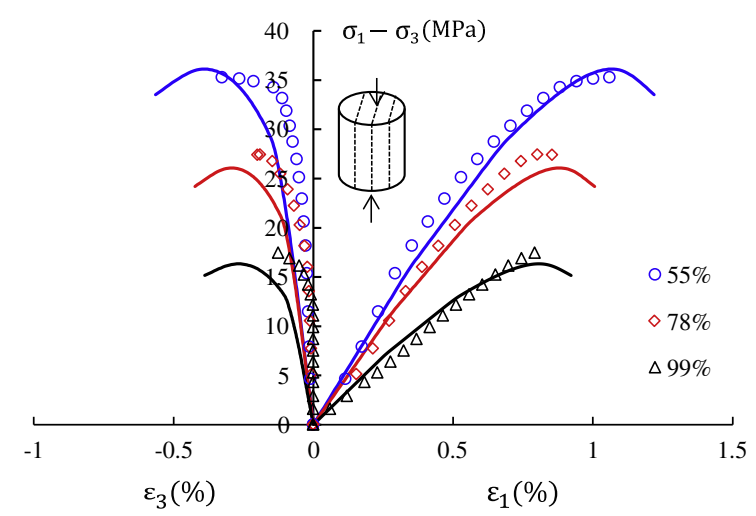

(b) Parallel bedding planes

Fig. 10. Simulation of uniaxial compression test under different relative humidities with vertical and parallel bedding planes. 
The typical values of model parameters for Meuse/Haute-Marne argillite are presented in Table 2 .

After identification of these parameters, the triaxial compression tests are simulated with different relative humidities as well as different orientations of the bedding planes relative to the loading direction. The results of the numerical simulations are provided in Figs. 8-10.

Fig. 8 presents the numerical simulations of the triaxial compression tests with normal bedding planes under three levels of relative humidity and four confining stresses. The simulation results of stress-strain curves are consistent with the experimental data in Fig. 8a-d. Fig. 8e shows the simulation results of volumetric strain $\varepsilon_{v}\left(\varepsilon_{v}=\varepsilon_{1}+2 \times \varepsilon_{3}\right)$-axial strain curves of triaxial compression tests with three levels of relative humidity and under confining stress of $20 \mathrm{MPa}$. The proposed model can predict the main phenomenon of volumetric strain evolution although there are some scatters between the simulation results and experimental data. In addition, the triaxial compression tests with cyclic loading under confining stress of $12 \mathrm{MPa}$ on samples with relative humidity of $78 \%$ are also simulated and the simulation results are presented in Fig. 10. Again, the simulation results are well consistent with the experimental data except for the volumetric strain-axial strain curves. This shortcoming in predicting of volumetric strain may be improved by choosing a more appropriate plastic yield function in the further work.

Fig. 10 presents the numerical simulations of uniaxial compression tests with normal and parallel bedding planes under three levels of relative humidity. A qualitatively good agreement exists between the numerical simulations and experimental data. The proposed model is able to take into account the double effects of relative humility and structural anisotropy. However, there is some scatter between the experimental data and the numerical simulations under high relative humidity for samples with normal bedding planes. This scatter is more significant when the confining stress is lower, especially for the case of uniaxial compression. During the re-saturation process, swelling of bedding planes occurs and thus their deformability becomes more important under higher relative humidity. In the case of perpendicular loading, the axial stress is applied normal to the bedding planes. Therefore, for the case of uniaxial compression (or low confining stress), the axial strain must undergo progressive closure of bedding planes before the linear elastic deformation step during axial stress loading. However, this progressive closure of the bedding planes cannot be considered in our proposed model and consequently results in the observed scatter. However, it is expected that the scatter could be easily reduced by using an improved description of the unilateral effects of microcracks from more complete test data.

\section{Conclusions}

In this study, we have presented an anisotropic poroelasticplastic damage model for partially saturated clayey rocks. The inherent anisotropy due to the bedding planes can also be considered using the discrete thermodynamic approach. The concept of effective stress is adopted to describe the effect of water content on the mechanical behavior. The proposed model is applied to triaxial compression tests of natural Tournemire argillite with different orientations of bedding planes, triaxial compression tests of Meuse/Haute-Marne argillite with different orientation of bedding planes and different water contents. Good agreement has been obtained between the numerical and experimental results. In summary, the proposed model can satisfactorily describe the inherent anisotropic properties of the material and the effect of water content on the mechanical behavior as well as their interaction in this material.

\section{Acknowledgements}

The authors wish to thank the reviewers for their constructive comments. The authors are grateful for financial support from the National Natural Science Foundation of China under the Grant Numbers 51009132, 50979104, 10972221 and 10672167 and from the French ANR Project MELANI.

\section{References}

[1] Zhang F. Comportement mécanique des argilites de MHM: influences de la saturation, de la composition minéralogique et de la température. Doctoral thesis, USTL, France; 2011.

[2] Richard TG, Advani SH. An experimental investigation of the combined effects of strain rate and moisture content on shale. Iss Rocks Mech 1982;23:315-23.

[3] Escoffier S. Caractérisation expériementale du comportement hydromécanique des argillites de Meuse/Haute Marne. Doctoral thesis, INPL Nancy, France; 2002.

[4] Chiarelli AS, Shao JF, Hoteit N. Modeling of elastoplastic damage behavior of a claystone. Int J Plast 2003;19:23-45.

[5] Zhang C, Rothfuchs T. Experimental study of the hydro-mechanical behavior of the Callovo-Oxfordian argillite. Appl Clay Sci 2004;26:325-36.

[6] Bemer E, Longuemare P, Vincké O. Poroelastic parameters of Meuse/Haute Marne argillites: effect of loading and saturation states. Appl Clay Sci 2004;26:366-9.

[7] Valès F, Nguyen Minh D, Gharbi H, Rejeb A. Experimental study of the influence of the degree of saturation on physical and mechanical properties in Tournemire shale (France). Appl Clay Sci 2004;26:197-207.

[8] Hoxha D, Giraud A, Homand F, Auvray C. Saturated and unsaturated behavior modeling of Meuse-Haute/Marne argillite. Int J Plast 2007;23(5):733-66.

[9] Fityus SG, Buzzi O. The place of expansive clays in the framework of unsaturated soil mechanics. Appl Clay Sci 2009;42:150-5.

[10] Zhang F, Xie SY, Hu DW, Shao JF, Gatmiri B. Effect of water content and structural anisotropy on mechanical property of argillite. Appl Clay Sci, in press.

[11] Alonso EE, Gens A, Josa A. A constitutive model for partially saturated soils. Géotechnique 1990;40(3):405-30.

[12] Coussy O, Eymard R, Lassabatère T. Constitutive modeling of unsaturated desaturation deformable materials. J Eng Mech 1998;124(6):658-67.

[13] Loret B, Khalili N. An effective stress elastic-plastic model for unsaturated porous media. Mech Mater 2002;34:97-116.

[14] Gray WG, Schrefler B. Thermodynamic approach to effective stress in partially saturated porous media. Eur J Mech A: Solids 2001;20:521-38.

[15] Shao JF, Jia Y, Kondo D, Chiarelli AS. A coupled elasotplastic damage model for semi-brittle materials and extension to unsaturated conditions. Mech Mater 2006;38:218-32

[16] Jia Y, Song XC, Duveau G, Su K, Shao JF. Elastoplastic damage modeling of argillite in partially saturated condition and application. Phys Chem Earth 2007;32:656-66.

[17] Kwasniewski MA. Mechanical behavior of anisotropic rocks. In: Comprehensive rock engineering: fundamentals, vol. 1. Oxford: Pergamon Press; 1993.

[18] Ramamurthy T. Strength and modulus responses of anisotropic rocks. In: Hudson JA, editor. Comprehensive rock engineering: fundamentals. vol. 1. Oxford: Pergamon Press; 1993.

[19] Lekhnitskii SG. Theory of elasticity of an anisotropic elastic body. San Francisco: Holden Day; 1963.

[20] Duveau G, Shao JF, Henry JP. Assesment of some failure criteria for strongly anisotropic geomaterials. Mech Cohes-Frict Mater 1998;3:1-26.

[21] Chen L, Shao JF, Huang HW. Coupled elastoplastic damage modeling of anisotropic rocks. Comput Geotech 2010;37:187-94.

[22] Amadei B. Rock anisotropy and the theory of stress measurements. Heidelberg: Springer; 1983.

[23] Niandou H, Shao JF, Henry JP, Fourmaintraux D. Laboratory investigation of the mechanical behavior of Tournemire shale. Int J Rock Mech Min Sci Geomech Abstr 1997;34:3-16.

[24] Pietruszczak S, Lydzba D, Shao JF. Modeling of inherent anisotropy in sedimentary rocks. Int J Solids Struct 2002;39:637-48.

[25] Lydzba D, Pietruszczak S, Shao JF. On anisotropy of stratified rocks: homogenization and fabric tensor approach. Comput Geotech 2003;30: 289-302.

[26] Min KB, Jing L. Numerical determination of the equivalent elastic compliance tensor for fractured rock masses using the distinct element method. Int J Rock Mech Min Sci Geomech Abstr 2003;40(6):795-816.

[27] Lee YK, Pietruszczak Z. Application of critical plane approach to the prediction of strength anisotropy in transversely isotropic rock masses. Int J Rock Mech Min Sci Geomech Abstr 2008;45(4):513-23.

[28] Coussy O. Poromechanics. Chichester: Wiley; 2004.

[29] Li XS. Thermodynamics-based constitutive framework for unsaturated soils 1 : theory. Géotechnique 2007;57(5):411-22.

[30] Li XS. Thermodynamics-based constitutive framework for unsaturated soils 2 : a basic triaxial model. Géotechnique 2007;57(5):423-35. 
[31] Miller GA, Khoury CN, Muraleetharan KK, Liu C, Kibbey TCG. Effects of solid deformations on hysteretic soil water characteristic curves: experiments and simulations. Water Resour Res J 2008;44:W00C06.

[32] Muraleetharan KK, Liu C, Wei C, Kibbey TCG, Chen L. An elastoplastic framework for coupling hydraulic and mechanical behavior of unsaturated soils. Int J Plast 2009;25:473-90.

[33] Wheeler SJ, Sharma RS, Buisson MSR. Coupling of hydraulic hysteresis and stress-strain behaviour in unsaturated soils. Géotechnique 2003;53(1): 41-54.

[34] Zhu QZ, Zhou CB, Shao JF, Kondo D. A discrete thermodynamic approach for anisotropic plastic-damage modeling of cohesive-frictional geomaterials. Int J Numer Anal Methods Geomech 2010;34:1250-70.

[35] Hu DW, Zhu QZ, Zhou H, Shao JF. A discrete approach for anisotropic plasticity and damage in semi-brittle rocks. Comput Geotech 2010;37(5):658-66.

[36] Thompson M, Willis JR. A reformulation of the equations of anisotropic poroelasticity. J Appl Mech ASME 1991;58:612-6.

[37] Cheng AHD. Material coefficients of anisotropic poroelasticity. Int J Rock Mech Min Sci 1997;34(2):199-205.
[38] Shao JF. Poroelastic behavior of brittle rock materials with anisotropic damage. Mech Mater 1997;30:41-53.

[39] Chateau X, Dormieux L. Mechanics of saturated and unsaturated porous media. Int J Numer Anal Methods Geomech 2002;26:821-44.

[40] Lyzeba D, Shao JF. Stress equivalence principle for saturated porous media. CR Mécan 2002;330:297-303.

[41] Hu DW, Zhou H, Shao JF. An anisotropic damage - plasticity model for saturated quasi-brittle materials. Int J Numer Anal Methods Geomech, in press. http://dx.doi.org/10.1002/nag.2103.

[42] Fredlund DG, Rahardjo H. Soil mechanics for unsaturated soils. New York: John Wiley \& Sons; 1993.

[43] Zhou Hui, Dawei Hu, Zhang Fan, Shao Jianfu. A thermo-plastic/viscoplastic damage model for geomaterials. Acta Mech Solida Sin 2011;24(3):195-208.

[44] Mazars J. Application de la mécanique de l'endommagement nonlinéaire et à la rupture du béton de structure. Doctoral thesis, Université de Paris; 1984 [in French].

[45] Hoek E, Brown ET. Underground excavations in rock. London: The Institute of Mining and Metallurgy; 1980 